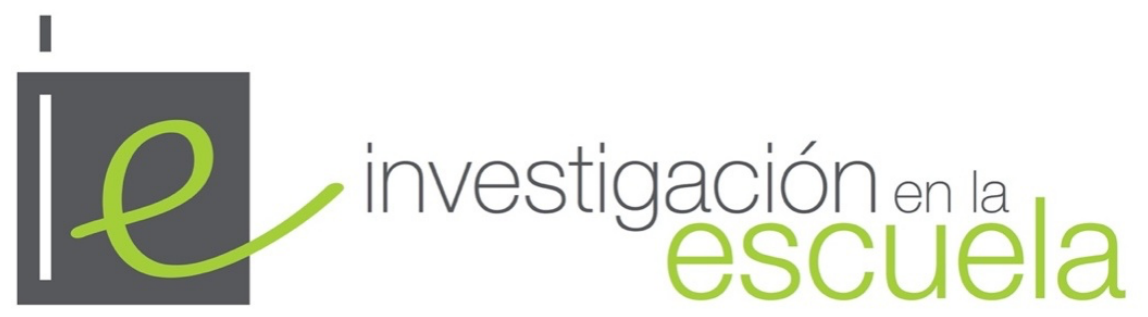

Revista de Investigación e Innovación Educativa nº 103, 2021 | e-ISSN 2443-9991

\title{
Desarrollo y evaluación de elementos de pensamiento crítico sobre la química verde en el bachillerato
}

Development and assessment of elements of critical thinking about green chemistry in high school

Dr. Jorge Meinguer Ledesma es Profesor Asociado en la Escuela Nacional Colegio de Ciencias y Humanidades de la Universidad Nacional Autónoma de México (México) · jorge.meinguer@cch.unam.mx https://orcid.org/0000-0001-7178-0882

Mtra. María del Consuelo Pérez Pérez es Profesora Interina en la Escuela Nacional Colegio de Ciencias y Humanidades de la Universidad Nacional Autónoma de México (México) · consuelo.perez@cch.unam.mx https://orcid.org/0000-0002-9678-2881

Cómo citar este artículo

Meinguer Ledesma, J. y Pérez Pérez, M.C. (2021). Desarrollo y evaluación de elementos de pensamiento crítico sobre la química verde en el bachillerato. Investigación en la Escuela, 103, 106-124. doi: http://dx.doi.org/10.12795/IE.2021.i103.08

Resumen. En este artículo se presentan los resultados encontrados al aplicar una estrategia didáctica que tuvo como finalidad desarrollar elementos de pensamiento crítico sobre la química verde en el bachillerato. La estrategia reportada es el resultado de incorporar y analizar un texto divulgativo sobre esta temática en el ámbito escolar, así como su problematización mediante la realización de actividades de indagación. En la primera parte de este escrito se ofrece una caracterización del pensamiento crítico que resulta compatible con el proceso de enseñanza-aprendizaje de la ciencia, se discute sobre algunas aportaciones que se asocian con el fomento de este tipo de pensamiento en la educación científica y se revisan algunos aspectos que justifican la pertinencia de la temática disciplinar que guió este estudio, la química verde. Posteriormente, se describe con detalle el contexto de aplicación y los logros obtenidos en materia de pensamiento crítico con la estrategia didáctica reportada. Finalmente, se analiza la viabilidad del trabajo metodológico emprendido y sus contribuciones al ámbito de la enseñanza de la química en general.

\begin{abstract}
This article presents the results found when applying a didactic strategy to develop elements of critical thinking on green chemistry in high school. The strategy reported is the result of incorporating and analyzing an informative text on this subject matter in the school environment, as well as its problematization through the conduct of inquiry activities. Firstly, this paper provides a characterization of critical thinking that is compatible with the teaching-learning process of science, discusses some contributions that are associated with the promotion of this type of thinking in science education, and reviews some aspects that justify the relevance of the disciplinary theme that guided this study: green chemistry. Subsequently, the implementation context and achievements in critical thinking obtained with the reported teaching strategy are described in detail. Finally, it analyses the feasibility of the methodological work undertaken and its contributions to the field of chemistry teaching in general.
\end{abstract}

\section{Palabras clave $\cdot$ Keywords}

Pensamiento crítico, química verde, indagación, enseñanza de la química, desarrollo sostenible, educación ciudadana. Critical thinking, green chemistry, inquiry, chemistry teaching, sustainable development, citizen education. 


\section{El pensamiento crítico en la educación científica}

Hoy en día, el término pensamiento crítico ha cobrado relevancia en el ámbito de la educación en general. Un hecho que se explica por varias razones, entre las que se puede destacar la necesidad de robustecer habilidades relacionadas con la búsqueda, manejo y validación de información, para superar déficits cognitivos asociados con la escasa capacidad que muestra el estudiantado para situar la relevancia de los aprendizajes disciplinares adquiridos en las aulas en el entorno social y cotidiano, así como para incentivar la participación informada en procesos de diálogo social. El pensamiento crítico al potenciar una acción intelectual que va desde la reflexión hasta la acción es referenciado por algunos autores como un logro epistémico que dota de rigor, autonomía, compromiso e integridad a la vida intelectual de las personas (Santisteban, 2013).

El término pensamiento es un sustantivo que proviene del latín pensare y que hace alusión al verbo pensar, una acción que en la literatura se asocia con la capacidad de recrear la realidad mediante estímulos internos y externos. Por otro lado, la palabra crítico procede del griego kritikos que posteriormente fue latinizada como criticus y que en español hace alusión a crítica, por lo que puede asociarse a toda acción que tiene como objeto criticar o problematizar. Uno de los primeros filósofos que relacionó el término de crítica con el razonamiento fue el filósofo Immanuel Kant (1724-1804). Para este pensador, la crítica puede contemplarse como un proceso que hace posible que la razón construya conocimientos fundamentados e incluso asoció a esta acción la función de dar legitimidad a todo intento de raciocinio (Kant, 2002). Tomando en cuenta lo anterior, el pensamiento crítico se puede definir de forma general como una acción intelectual encaminada al análisis o problematización racional de un tema, fenómeno o hecho de interés. Su propósito es generar cuestionamientos, mejores juicios y razonamientos orientados a una mejor comprensión del mundo (Meinguer, 2018).

En el ámbito de la educación científica, al pensamiento crítico se le suele conceptualizar como un medio que favorece la comprensión reflexiva y significativa de los contenidos curriculares, la resolución de problemas, así como la toma de decisiones (Oliveras et al., 2013). A pesar de su amplio reconocimiento en el discurso educativo y social contemporáneo, algunos autores sostienen que la promoción sistematizada del pensamiento crítico en el ámbito escolar es escasa debido a la falta de claridad que impera en los docentes sobre su significado, sus objetivos más inmediatos, sus alcances, así como su valor tanto dentro como fuera de las aulas (Wright, 2002; Herrera, 2008). Para contribuir a este problema, en este apartado se ofrece una breve caracterización del pensamiento crítico desde una perspectiva analítica, ya que esta visión de la criticidad es la que ha tenido mayores repercusiones en el campo de la pedagogía y la investigación educativa.

En el campo de la filosofía analítica, el término "critical thinking" (pensamiento crítico) comenzó a figurar a mediados de la década de los setenta, en un movimiento que se generó en países anglosajones por profesores insatisfechos con los logros de aprendizaje obtenidos en los cursos tradicionales de lógica formal o proposicional. Como alternativa, este movimiento académico promovió la enseñanza del pensamiento crítico, un objetivo que desde sus inicios se vinculó con el análisis del razonamiento de lo cotidiano (Herrera, 2008). Esta perspectiva de la criticidad fue cobrando relevancia en la educación gracias a los trabajos del denominado grupo de los cinco, un núcleo de filósofos norteamericanos que ejercieron activamente la docencia y realizaron contribuciones valiosas acerca del importante papel que juega el pensamiento crítico en la formación intelectual de las personas. El grupo de los cinco constituye un referente en la literatura sobre pensamiento crítico y está integrado por John McPeck, Robert Ennis, Harvey Siegel, Matthew Lipman y Richard Paul (Boisvert, 2004). Los trabajos de este último son los que han tenido mayor impacto en el campo de la enseñanza de las ciencias. Por tal razón, su visión de la criticidad constituye el basamento teórico de esta investigación.

Según Paul y Elder (2007), el pensamiento crítico puede definirse como un modo de pensar sobre cualquier tema, contenido o problema, en el que un sujeto mejora la calidad de su pensamiento inicial. Esta definición del pensamiento crítico se basa en una articulación sistemática que involucra tres rubros: elementos de pensamiento, estándares y virtudes intelectuales. La conjunción de estos elementos hace que el pensamiento crítico sea un proceso autodirigido, autodisciplinado y autorregulado, pues implica desarrollar habilidades orientadas a la resolución efectiva de problemas, así como someterse a rigurosos estándares en su evaluación (Paul y Elder, 2006).

En esta noción del pensamiento crítico, la comprensión profunda y reflexiva de un contenido o tema disciplinar, es el resultado de la articulación de ocho elementos: 1) un propósito, objetivo o meta; 2) el intento de dar solución a una pregunta, problema o la necesidad de explicar algo; 3) el manejo de información; 4) la formulación de inferencias y juicios para llegar a conclusiones sólidas; 5) el reconocimiento de los supuestos o ideas implícitas que se dan por hecho en el estudio de una temática específica; 6) el manejo de teorías y conceptos que se consideran clave para comprender un fenómeno 
dentro de una disciplina; 7) la identificación de las implicaciones y consecuencias asociadas en el análisis de un tema y 8) la consideración de diferentes puntos de vista que giran alrededor de un contenido o temática en cuestión. La articulación de estos elementos permite la construcción de relaciones explicativas basadas en la coherencia, las cuales favorecen el entendimiento disciplinar.

Figura 1

Elementos del pensamiento crítico según Pauly Elder (2006)

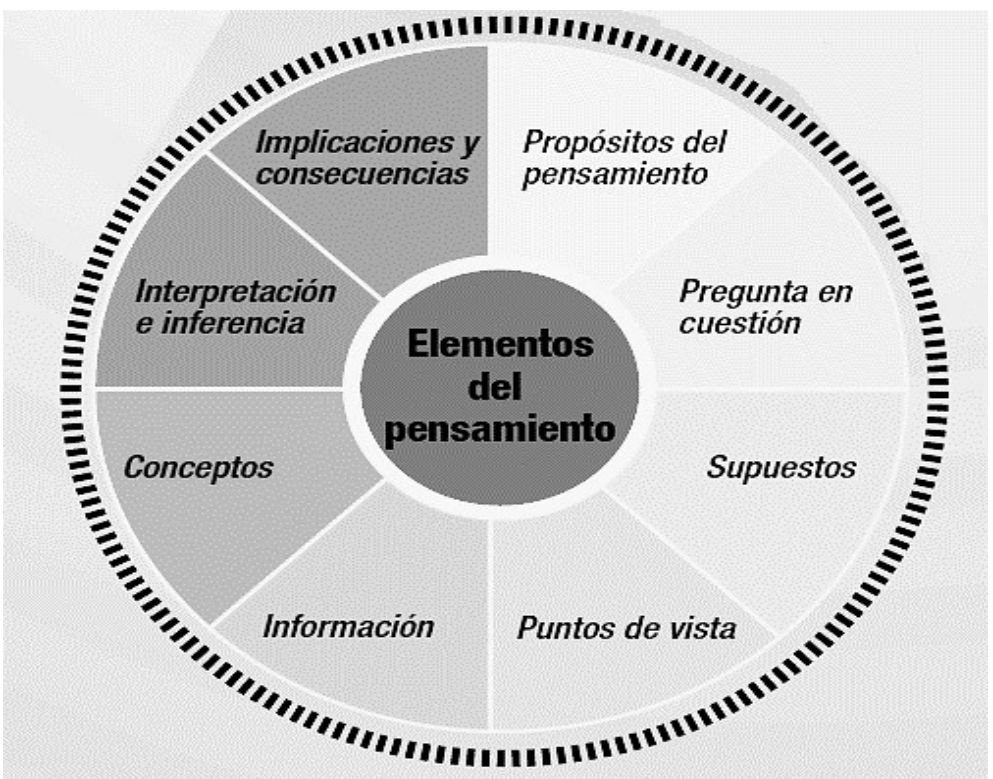

El segundo aspecto por considerar son lo que Paul y Elder (2006) denominan estándares intelectuales. Estos son criterios útiles para valorar la calidad del razonamiento sobre un problema o contenido de interés. En otras palabras, permiten reconocer el grado de desarrollo de los ocho elementos antes mencionados y ayudan a manejar y procesar la información con rigor y autonomía. Los estándares presentes en esta visión del pensamiento crítico son exactitud, claridad, relevancia, lógica, profundidad, amplitud e imparcialidad (Paul y Elder, 2007). El tercer elemento que configura a esta noción de la criticidad es el desarrollo de una serie de cualidades disposicionales que Paul y Elder (2006) denominan características o virtudes intelectuales. En este núcleo disposicional figura la formación de aptitudes como la honestidad, autonomía, integridad y perseverancia intelectual, cualidades con las que se puede trazar un puente con el aprendizaje actitudinal. A este núcleo disposicional, se le suele agrupar en la epistemología analítica bajo una noción más general denominada responsabilidad epistémica (Code, 2011). Bajo esta perspectiva, la justificación de los logros cognitivos guarda una estrecha relación con el proceder de un sujeto al llevar a cabo una tarea o actividad intelectual. En este contexto la responsabilidad puede asumirse como un medio para acentuar y reconocer la naturaleza activa de un buen conocedor. En el caso concreto del pensamiento crítico, la responsabilidad está asociada con la búsqueda, la selección, así como el uso que se le da al conocimiento y la información al construir un entendimiento reflexivo de un tema y participar tanto en su análisis como su discusión (Meinguer, 2018).

Son tres las ventajas o contribuciones que se asocian con la promoción del pensamiento en la educación científica. La primera es que como se ha reiterado, la criticidad del pensamiento está ligada con un entendimiento profundo, reflexivo y situado de los contenidos disciplinares. Un logro cognitivo que posibilita al estudiantado reconocer la validez, la consistencia y el significado de la información disciplinar que se comunica en las aulas. La segunda contribución es que incentiva la indagación y la argumentación escolar, ya que, al ser un proceso basado en el análisis coherente de la información, su impulso puede coadyuvar al reconocimiento de presupuestos subyacentes en la construcción de aprendizajes, la metacognición y la acción comunicativa. La tercera es que al tener un importante componente disposicional favorece la participación, el diálogo, la interacción y la colaboración escolar (Jiménez-Aleixandre y Puig, 2012). Capacidades ampliamente reconocidas en la pedagogía contemporánea (Alvarado, 2014). A manera de síntesis, se puede aseverar que el pensamiento crítico es un elemento clave en la denominada educación ciudadana (Santisteban, 2013). 


\section{El estudio de la sostenibilidad y la química verde en el bachillerato}

Una temática que se considera relevante en la educación científica contemporánea es el desarrollo sostenible. Un término que fue definido por primera vez en 1987 por la Comisión Mundial para el Ambiente y el Desarrollo de las Naciones Unidas, como el desarrollo que satisface las necesidades de la generación presente sin comprometer las capacidades y los recursos de las generaciones futuras (ONU, 1987). Para algunos autores, la noción de desarrollo sostenible no solamente tiene como meta garantizar el bienestar de generaciones futuras sino también preservar el mayor tiempo posible, las mejores condiciones de vida para todos los seres vivos que habitan el planeta (Reyes-Sánchez, 2012; Rodríguez, 2018). Actualmente, la Organización de las Naciones Unidas asocia al desarrollo sostenible diecisiete objetivos en los que destaca además de la preservación ambiental, el combate a la pobreza, la desigualdad y el hambre, así como la promoción de la igualdad de género y de una educación de calidad para todos los sectores sociales (ONU, 2019).

En el ámbito educativo la ONU en una publicación denominada "Carta de la Tierra" publicada en el año 2000, relaciona el término de sostenibilidad con una formación que posibilite a los educandos la adquisición de una conciencia que coadyuve al establecimiento de formas o modelos de vida que sean respetuosos de la naturaleza y cuidadosos del equilibrio planetario (ONU, 2000). En ese sentido la UNESCO señala que impulsar una educación basada en el desarrollo sostenible posibilita a los estudiantes la toma de decisiones informadas y la adopción de medidas responsables en favor de medio ambiente, la viabilidad económica y la edificación de una cultura social para las generaciones actuales y futuras, respetando la diversidad cultural (UNESCO, 2017). Desde esta perspectiva, la Educación para el Desarrollo Sostenible (EDS) se contempla como un proceso holístico y transformador que se cultiva durante toda la vida. Para algunos especialistas en el tema como Vilches y Gil, los ejes que deben guiar a una educación para el desarrollo sostenible deben ser el estudio de los aspectos físicos, químicos y biológicos producto de la actividad humana que tienen incidencia directa en el deterioro ambiental, enfatizando la atención en la relación entre el desarrollo científico y económico con la mitigación de este problema, así como pugnar por una solidaridad mundial en el cuidado del planeta (Vilches y Gil-Pérez, 2013). Otros fines que estos autores vinculan con la EDS son el consumo responsable, la transición energética, revertir la acelerada pérdida de biodiversidad, proteger la diversidad cultural, aminorar el crecimiento poblacional y avanzar hacia una gobernanza plenamente democrática (Gil y Vilches, 2019).

Una educación para el desarrollo sostenible exige de las comunidades docentes y científicas respuestas resilientes en torno a los diversos problemas ambientales que se padecen en la contemporaneidad, la formación de una visión crítica de estos problemas en las aulas y el fomento de la participación informada en el alumnado. Algunos especialistas están señalando, la necesidad de incorporar en la EDS la noción de decrecimiento, ya que desde esta óptica es posible enfatizar aspectos relacionados con los límites biofísicos del planeta y la necesidad de un cambio en el modelo de desarrollo (García-Díaz et al., 2019). Para estos autores una genuina educación ambiental implica fomentar un "saber hacer" basado en el manejo de tecnologías y metodologías más resilientes. En este contexto contenidos como ecosociosistemas, ciclos y flujo de energía en la biosfera, agotamiento de recursos, huella ecológica y cambio climático adquieren relevancia. En el terreno de la química existe una rama de conocimientos que guarda una fuerte relación con el desarrollo sostenible y con el establecimiento de metodologías ambientalmente resilientes, la denominada química verde.

El campo de la química verde tiene su origen en publicaciones realizadas en la segunda mitad de la década de los noventa por los químicos norteamericanos Anastas y Warner (1998), en estos trabajos se proponen 12 principios como una guía en su conducción y regulación (figura 2). De manera concreta, la química verde se puede definir como una metodología cuyos objetivos están orientados en el diseño de procesos químicos que permitan disminuir o eliminar el uso de sustancias tóxicas que resultan peligrosas para la salud y el medio ambiente (Morales et al., 2011). Una labor que implica innovar o rediseñar una gama de procesos de síntesis en donde se prioriza el control y la economía atómica, la catálisis, el uso de disolventes alternativos, la eficiencia energética, el empleo de materias primas renovables y la reducción de productos derivados en las reacciones químicas. La filosofía de trabajo de la química verde busca prevenir la contaminación en lugar de remediarla, esto mediante el establecimiento de procesos más limpios, biodegradables, económicos y eficientes (Sierra et al., 2014). Una cuestión que abona en el ámbito educativo a optimizar, racionalizar y dotar de sentido al trabajo experimental que diseña el profesorado en el laboratorio químico escolar, así como a dar cauce a contenidos relacionados con la sostenibilidad (Ribeiro y Machado, 2013). 


\section{Figura 2}

Los doce principios de la quimica verde (Rodríguez, 2018)

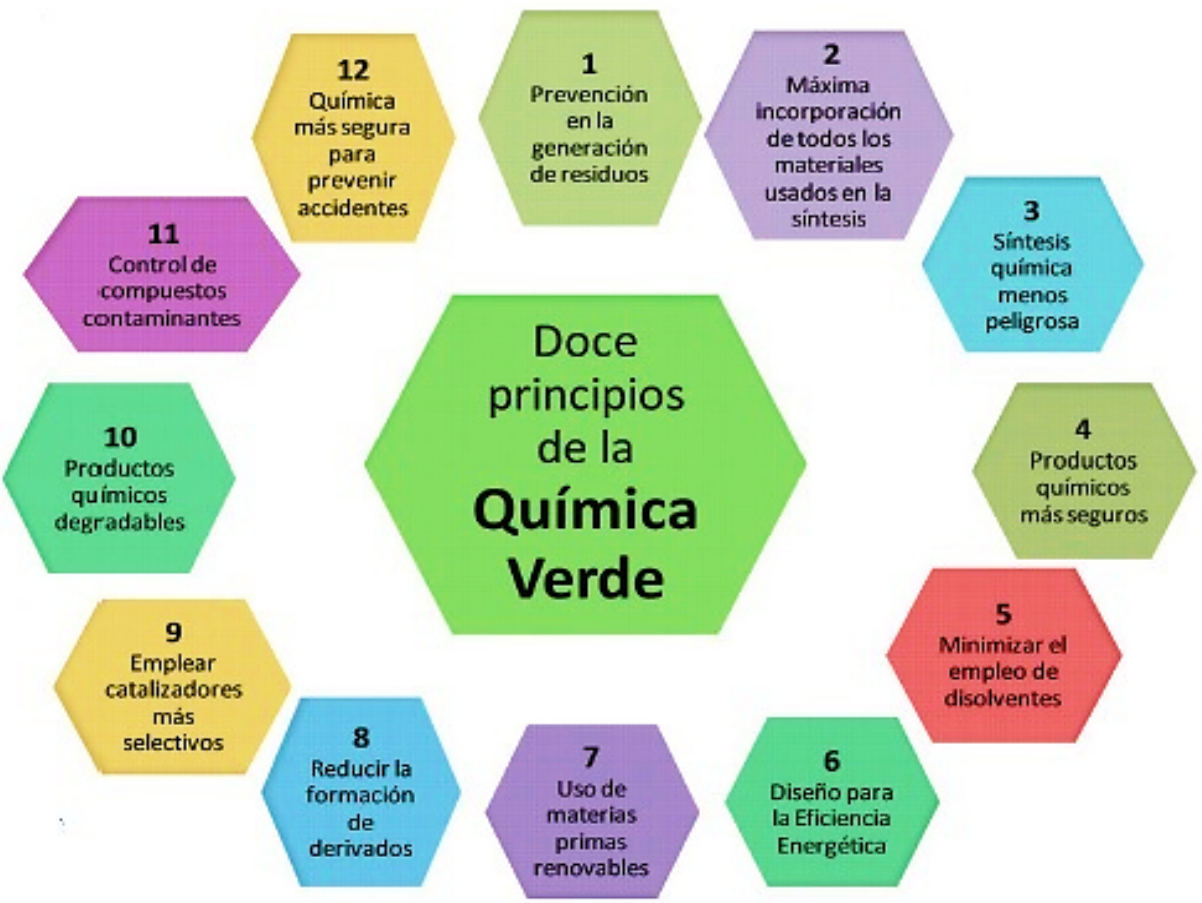

Tomando en cuenta lo expuesto en párrafos anteriores, se puede aseverar que comunicar aspectos relevantes sobre la química verde en el contexto escolar, resulta una labor pertinente y apremiante porque posibilita mostrar a los alumnos las nuevas directrices que ha tomado la investigación química para adaptarse y contribuir al paradigma de sostenibilidad. Aspectos que proveen de actualidad al proceso de enseñanzaaprendizaje de esta ciencia, promueven la reflexión y la construcción de aprendizajes significativos. También, permiten presentar a la química en las aulas y los laboratorios como una ciencia que incide de manera efectiva en la resolución de problemas de interés socioambiental. Un hecho que contribuye a mejorar su percepción pública en contextos escolares (Meinguer, 2015).

\section{La lectura como estrategia para fomentar el pensamiento crítico y la indagación}

La lectura constituye uno de los pilares sobre los que está cimentada la educación, gracias a ella es posible desarrollar una serie de habilidades cognitivas que se ponen en marcha durante toda la vida. En tratados educativos internacionales como el proyecto PISA-OECD, la definen como una aptitud basada en comprender, analizar y utilizar textos escritos con el fin de lograr objetivos personales, desarrollar conocimientos y posibilidades que faciliten la participación plena en la sociedad (OECD, 2007). El proceso de lectura ya sea dentro como fuera del aula permite que los estudiantes se apropien de nuevos conocimientos, aprendan el lenguaje de la ciencia y puedan confrontar sus puntos de vista con otras personas (Marbá et al., 2009). Es por ello que, la educación científica debería estimular más el hábito de leer, pues es una labor que contribuye a edificar una formación integral en el estudiantado. Sin embargo, la tendencia no ha ido en esta dirección. La falta de interés del alumnado sobre los textos científicos tradicionales -y por la ciencia en general-, ha ocasionado que los docentes simplifiquen al máximo la actividad lectora. Como resultado sigue predominando en las aulas y laboratorios de ciencia, la revisión de manuales, diapositivas y libros de texto que son usados para la memorización de información, en lugar de recursos y estrategias centrados en su interpretación crítica.

Para revertir esta situación, varios académicos han planteado la necesidad de redimensionar el papel de la lectura en la educación científica, así como ampliar el abanico de recursos textuales presentes en la enseñanza incorporando material periodístico y divulgativo (Cassany, 2010; Gordillo, 2005). Considerando lo anterior, en este trabajo se propone dar cauce al estudio de la química verde partiendo de la lectura, el análisis y la problematización de un artículo de divulgación científica. La razón que respalda esta decisión se 
debe a que este tipo de fuentes al presentar la información de forma clara, sencilla y contextualizada suelen resultar de mayor agrado e interés para los estudiantes de bachillerato (Halkia y Matzouridis, 2005).

Algunos autores han propuesto utilizar la ciencia que se divulga en los medios de comunicación escrita para fomentar el pensamiento crítico en las clases de ciencias (Norris et al., 2003; McClune y Jarman, 2012; Oliveras et al., 2013). La idea de promover el pensamiento crítico hacia el discurso mediático sobre ciencia y tecnología se fundamenta en tres razones. La primera de ellas se relaciona con el hecho de que estos recursos textuales representan una de las vías principales con las que los estudiantes mantendrán contacto con el desarrollo científico fuera de las aulas, independientemente de su grado escolar o perfil profesional. La segunda, con que suelen abordar temáticas de frontera, las cuales además de dotar de actualidad al proceso de enseñanza de las disciplinas científicas son de interés público, ya que su análisis involucra la consideración de derechos, intereses y obligaciones. La tercera se asocia con la alta carga de subjetividad que caracteriza al discurso mediático sobre ciencia y tecnología, una cuestión que puede moldear malintencionadamente las opiniones e inclusive las acciones de las personas. Por consiguiente, resulta crucial preparar a los alumnos desde la escuela para interpretar meticulosa y reflexivamente este tipo de publicaciones, así como para usar la información consultada de manera responsable (Meinguer, 2019).

La incorporación de textos de corte divulgativo en el ámbito escolar se puede asociar también con el impulso de la indagación, una actividad que en la educación científica se relaciona con fomentar la curiosidad, la investigación y la explicitación de puntos de vista mediante actividades donde los estudiantes adopten un papel activo en la construcción de aprendizajes (Garritz, 2010). Esto debido a que, en la decodificación o problematización de este tipo de fuentes se pueden plantear actividades abiertas que impliquen la realización de investigaciones documentales con ayuda de las TIC, la experimentación para recabar evidencias y reforzar conceptos claves, así como la elaboración de productos que induzcan a los alumnos a argumentar posicionamientos, consideraciones, puntos de vista y conclusiones en torno a un tema o contenido en estudio.

\section{Metodología}

El objetivo central de esta investigación fue implementar una estrategia educativa basada en el análisis y problematización de un texto divulgativo para promover elementos de pensamiento crítico sobre la química verde en el bachillerato. En esta los alumnos realizaron diversas actividades y productos basados en la indagación, los cuales estuvieron orientados a reforzar el aprendizaje de contenidos clave y la reflexión sobre el contexto de aplicación del tema.

\subsection{Contexto de aplicación de la secuencia didáctica}

La estrategia educativa reportada en esta investigación se aplicó en el mes de octubre de 2019 con dos grupos que cursaban la asignatura de Química III en el Colegio de Ciencias y Humanidades, una institución que forma parte del bachillerato de la Universidad Nacional Autónoma de México (UNAM). Esta materia constituye el penúltimo curso de química que se imparte en esta institución educativa y tiene un carácter propedéutico, por lo que puede considerarse un curso de química preuniversitario. El estudio de la química verde se situó en el marco de la primera unidad de dicha asignatura que lleva por título: Industria Química en México factor de desarrollo. En este espacio curricular, se da pauta a referenciar diferentes aspectos de la química y su industria que tengan como finalidad contribuir al desarrollo sostenible (UNAM-CCH, 2016).

La mayoría de las sesiones de trabajo se efectuaron en la sala de cómputo y solamente una en el laboratorio de química de la institución educativa correspondiente. La estrategia didáctica fue implementada con dos grupos o aulas de trabajo, las cuales fueron divididas en pequeñas agrupaciones de 4 a 5 estudiantes, lo que permitió conformar 11 equipos de trabajo $(\mathrm{n}=11)$, cuyo desempeño fue la base para dar seguimiento a las actividades cooperativas. En el trabajo individual, fueron 45 el total de estudiantes participantes $(n=45)$. Los alumnos fueron notificados previamente que, los productos elaborados y su participación en este estudio serían reportados en un trabajo de investigación y a dependencias institucionales que apoyaron la realización del proyecto que se presenta en este manuscrito. En la tabla 1, se ofrecen características específicas de los estudiantes participantes. 
Tabla 1

Características de los estudiantes participantes en este estudio

\begin{tabular}{lllll}
\hline Grupo & \multicolumn{1}{c}{$\begin{array}{c}\text { Edad } \\
\text { promedio }\end{array}$} & Integración por género & Total & $\begin{array}{c}\mathbf{N}^{\mathbf{0}} \text { de equipos de } \\
\text { trabajo }\end{array}$ \\
\hline I & 17 años & 16 varones; 8 mujeres & 24 alumnos & 6 \\
II & 17 años & 7 varones; 14 mujeres & 21 alumnos & 5 \\
Totales & & 23 varones; 22 mujeres & 45 alumnos & $\mathbf{1 1}$ \\
\hline
\end{tabular}

\subsection{Secuencia de actividades}

Como se mencionó en el marco teórico, en este estudio para promover el pensamiento crítico se ha tomado como referente la visión de Paul y Elder (2007). Desde esta perspectiva, para fomentar un entendimiento riguroso, duradero y reflexivo de un tema o contenido disciplinar, es necesario que este sea analizado a partir de ocho elementos que al ser articulados de forma coherente permiten establecer relaciones explicativas y la construcción de conclusiones veraces con cierta objetividad. El tipo de preguntas que fungieron como guía para suscitar el desarrollo de dichos elementos en el proceso de análisis del texto divulgativo, se muestran en la figura 3.

Figura 3

Preguntas orientadoras para desarrollar elementos de pensamiento crítico (Pauly Elder, 2007)

\begin{tabular}{ll} 
Elementos & PReguntas \\
\hline Propósito & ¿Qué trato de lograr? \\
\hline ¿Cuál es mi meta central? ¿Cuál es mi propósito? \\
\hline Información & ¿Qué pregunta estoy formulando? \\
& ¿Qué pregunta estoy respondiendo? \\
\hline ¿Qué información estoy usando para llegar a esa conclusión? & ¿Qué experiencias he tenido para apoyar esta afirmación? \\
¿Qué información necesito para resolver esa pregunta?
\end{tabular}

Las actividades realizadas durante el proceso de análisis textual en torno a la química verde se secuenciaron en cuatro etapas, cada una de ellas se trabajó en una sesión de dos horas, por lo que la duración total de la secuencia educativa implementada fue de ocho horas. Las primeras tres se llevaron a cabo en una dinámica de trabajo cooperativo en pequeños grupos, mientras que la última sesión relacionada con la elaboración de un producto argumentativo sobre el tema se llevó a cabo de forma individual. Las actividades implementadas en cada etapa se describen a continuación:

i. Exploración de conocimientos previos y análisis de un texto divulgativo. En la primera sesión de trabajo se explicitaron los objetivos de aprendizaje de la secuencia de actividades por emprender y se exploraron asociaciones conceptuales iniciales de los estudiantes en torno a la química verde. Posteriormente, los alumnos analizaron un texto divulgativo con el propósito de que adquirieran un panorama general sobre el tema. El material de lectura revisado lleva por título "La Química Verde" y fue escrito por Ruíz-Loyola y Ruíz-Gutiérrez (2011) para la editorial ¿Cómo ves?, la revista de divulgación científica más importante y representativa de la UNAM. Se determinó utilizar este texto por el correcto tratamiento de los contenidos abordados y porque en su presentación se utiliza un discurso que resulta adecuado para estudiantes de bachillerato. 
ii. Realización de un experimento. En la segunda sesión de trabajo se llevó a cabo la actividad experimental: ¿Qué tan verde es una reacción química? En esta los alumnos efectuaron la reacción de descomposición del agua oxigenada utilizando dos catalizadores uno tradicional, el óxido de manganeso (IV) y otro natural, la enzima catalasa presente en vegetales ricos en almidón como la papa o chirivía. En el experimento los estudiantes utilizaron pequeños trozos de papa para desencadenar la descomposición del agua oxigenada. Posteriormente, al utilizar la adaptación de un instrumento de evaluación reportado por Vargas et al. (2016), los alumnos identificaron cuál de las dos reacciones efectuadas cumplía con mayor número de postulados de la química verde. La realización de esta breve actividad experimental permitió reforzar aprendizajes disciplinares claves como el postulado 9 de la metodología verde (figura 2), el cual fue revisado en el texto divulgativo.

iii. Breve investigación documental. La tercera sesión estuvo basada en la indagación de aspectos contextuales referenciados en el texto divulgativo. Concretamente, los estudiantes investigaron datos y cifras sobre el reciclaje del PET (polietilenteraftalato), un polímero utilizado en el envasado de bebidas y alimentos. En el texto revisado en clase los procesos de reciclaje son mencionados con el propósito de que los jóvenes infieran la relación que tienen estos con la filosofía que da sustento a la química verde (principios 1 y 11 esquematizados en la figura 2) y con la noción de desarrollo sostenible. Auxiliándose de internet, los estudiantes buscaron información sobre la cantidad de PET que se recicla en México, así como de las implicaciones económicas, sociales y ambientales que se asocian con esta actividad. Acto seguido, expusieron sus resultados en una plenaria o espacio de discusión conducido y supervisado por los docentes a cargo.

Tabla 2

Descripción sintética de las actividades realizadas por sesión

\begin{tabular}{lll}
\hline \multicolumn{1}{c}{ Sesiones/modalidad } & \multicolumn{1}{c}{ Actividades/Productos } \\
\hline & $>$ & Contextualización: presentación de los objetivos y \\
I. Exploración de conocimientos previos & sentido de las actividades por emprender. \\
y análisis del contenido de un texto & Exploración de conocimientos previos sobre la \\
divulgativo / Trabajo cooperativo & química verde. \\
$(\mathrm{n}=11)$ & Revisión del contenido del artículo divulgativo: \\
Tiempo total: 120 minutos & Ruíz-Loyola, B. y Ruíz-Gutiérrez, J. (2011). La Química \\
& Verde, ¿Cómo ves? UNAM, 150, 30-33. \\
Productos: Cuestionario 15 preguntas
\end{tabular}

II. Actividad experimental: ¿Qué tan verde es una reacción química? /

Trabajo cooperativo $(\mathrm{n}=11)$

Tiempo total: 120 minutos

III. Investigación Documental: Reciclaje del PET en México/ Trabajo cooperativo $(\mathrm{n}=11)$

Tiempo total: 120 minutos

IV. Elaboración de un escrito final sobre la relevancia del tema/ Trabajo individual $(\mathrm{n}=45)$

Tiempo total: 120 minutos
> Realización de la actividad experimental: ¿Qué tan verde es una reacción quimica? Descomposición del $\mathrm{H}_{2} \mathrm{O}_{2}$ con dos catalizadores $\left(\mathrm{MnO}_{2}\right.$ y enzima catalasa).

$>$ Interpretación del experimento con una tabla basada en los 12 principios de la química verde (Vargas et al., 2016)

Productos: Resultados obtenidos con la tabla de evaluación verde y cuestionario de 5 preguntas.

Investigación en internet sobre diferentes aspectos relacionados con la industria del PET en México.

$>$ Foro de discusión de los resultados obtenidos en la investigación documental y sobre su relación con la filosofía de la química verde y el desarrollo sostenible.

Productos: Informe de investigación documental y tabla utilizada para organizar la información vertida en el foro de discusión.

Obtención del primer borrador del escrito final sobre la relevancia disciplinar, ambiental y educativa de la química verde.

Coevaluación del borrador en una dinámica de pares. 
Productos: Primer borrador, lista de cotejo de coevaluación y versión final del escrito.

iv. Elaboración de un escrito final. Para dar cierre al trabajo metodológico, se solicitó a los estudiantes que elaboraran un ensayo donde explicitarán la importancia disciplinar, ambiental y educativa del tema estudiado. Este escrito constituyó el producto final de la secuencia didáctica. En la cuarta sesión se obtuvo el primer borrador de este escrito, el cual fue coevaluado en una dinámica de pares usando una lista de cotejo. La versión final del ensayo fue elaborada por los alumnos como actividad extraclase.

El esquema pedagógico que se siguió en la implementación de la estrategia estuvo basado en el trabajo colaborativo, el diálogo, la interacción y la mediación docente como una vía en la autorregulación del aprendizaje, esto es, en un marco pedagógico horizontal que resulta acorde con la enseñanza del pensamiento crítico (Alvarado, 2014).

\subsection{Instrumentos utilizados para evaluar el desarrollo del pensamiento crítico}

Para dar seguimiento al desarrollo del pensamiento crítico, en la literatura se recomienda seguir una ruta de evaluación que permita valorar de forma cualitativa y progresiva los logros conseguidos (Jarman y McClune, 2007; Oliveras et al., 2013). El uso de rúbricas es de gran utilidad para dar cumplimiento a este fin. En la literatura una rúbrica se define como una guía que permite dar seguimiento y situar en niveles o puntajes específicos, el aprovechamiento observado en los alumnos en torno a aprendizajes, habilidades o actitudes que guardan relación con objetivos o metas educativas que se consideran complejas y subjetivas (Gatica-Lara y Urribarren-Berrueta, 2013), como es el caso del pensamiento crítico.

En este estudio se utilizaron como instrumentos de evaluación dos rúbricas, la primera está basada en los ocho elementos del pensamiento crítico y los indicadores propuestos para su evaluación por Paul y Elder (2007). La segunda fue utilizada para evaluar habilidades argumentativas sobre la química verde y corresponde a un instrumento de evaluación reportado en una investigación previa (Meinguer, 2019) esta segunda rúbrica permite valorar aspectos esenciales que los alumnos deben cumplir para mostrar una opinión o conclusión fundamentada sobre un tema. En estos dos instrumentos, los indicadores de desempeño están agrupados en una escala de puntuación de 1 a 4. De modo que, la calificación de 1 denota una ejecución deficiente, 2 un desempeño suficiente, 3 un aprovechamiento regular y 4 una ejecución óptima. Por su parte, la tabla con criterios para valorar que tan verde es una reacción química fue readaptada de un trabajo reportado por Vargas et al. (2016).

Con la primer rúbrica basada en los ocho elementos de pensamiento crítico (Paul y Elder, 2007) se evaluaron los siguientes productos mencionados en la tabla 2 de la sección anterior, el cuestionario de 15 preguntas sobre el análisis de contenido del texto divulgativo (sesión 1), el cuestionario de la actividad experimental efectuada (sesión 2), así como el informe que prepararon los alumnos sobre en torno al reciclaje del PET y la tabla donde organizaron la información más relevante en el espacio de discusión sobre este tema (sesión 3). La adaptación de la tabla con los 12 principios de la química verde (Vargas et al., 2016) fue usada para reconocer aquellos principios que los alumnos asociaron a las dos reacciones efectuadas en la actividad experimental (sesión 2), un aspecto que les permitió justificar su elección sobre cuál se considera más verde. Finalmente, la rúbrica de habilidades argumentativas se utilizó para evaluar los ensayos que elaboraron de forma individual los estudiantes sobre la relevancia que posee el estudio de la química verde (sesión 4), es decir, el producto final de la estrategia didáctica implementada. Los instrumentos de evaluación utilizados y descritos en esta sección se presentan en el anexo que acompaña a este artículo.

Los productos que elaboraron los estudiantes se obtuvieron de forma física y fueron agrupados y analizados en dos categorías por separado, cooperativos e individuales. Para su evaluación, la organización y presentación de resultados se hizo uso de un software basado en hojas de cálculo y estadística descriptiva. La integración de los resultados conseguidos en ambas categorías se discute en la siguiente sección de este manuscrito.

\section{Análisis y resultados}

Los logros obtenidos en este estudio se presentan en dos etapas. En la primera se describen los resultados conseguidos en el desarrollo de elementos de pensamiento crítico sobre la química verde en las actividades que se trabajaron de forma cooperativa. En la segunda se reporta el desempeño individual observado en materia de argumentación sobre el tema. La articulación de los resultados conseguidos en 
ambas etapas, constituye la evidencia que permite sostener la construcción de una interpretación crítica sobre la química verde con la metodología reportada.

\subsection{Desarrollo de elementos de pensamiento crítico sobre la química verde}

$\mathrm{Al}$ revisar el producto que elaboraron los estudiantes participantes en la primera sesión de la estrategia educativa reportada (cuestionario de 15 preguntas), se observó que en aquellas preguntas que tenían como propósito explorar conocimientos previos, los estudiantes definieron a la química verde como una parte del conocimiento químico que tiene como objetivo contribuir a reducir la contaminación ambiental, en menor medida algunos alumnos relacionaron a esta área con el estudio de los productos naturales. Ideas que son en cierto grado correctas. Sin embargo, cuando se solicitó que explicitarán conocimientos en torno a su marco de acción, es decir, como este campo da cumplimiento a sus objetivos principales, los alumnos se limitaron a parafrasear algunos subtítulos o párrafos iniciales de la publicación divulgativa por analizar. Un hecho que evidenció que sus nociones o conocimientos previos sobre el tema eran limitados. Con el avance de la implementación de la propuesta metodológica reportada, como se informa al analizar los resultados conseguidos con la rúbrica empleada para evaluar habilidades argumentativas en párrafos posteriores, su conceptualización y dominio de esta temática disciplinar mejoró significativamente. Explorar ideas previas permitió reconocer el avance conceptual sobre el tema y reforzar conceptos clave en su abordaje. Las nociones disciplinares que se reforzaron durante la segunda sesión de trabajo (al efectuar una actividad experimental) fueron reacción química, la función de los catalizadores, los conceptos de átomo y molécula al explicar el cambio químico, así como la aplicación de los doce principios de la química verde en el laboratorio químico escolar.

Es importante mencionar que, el seguimiento del desarrollo de algunos elementos de pensamiento crítico se realizó de manera puntual durante el análisis del contenido del artículo divulgativo y otros por su relevancia y características propias fueron evaluados de forma transversal, es decir, tomando en consideración el desempeño global de los 11 equipos de trabajo durante la realización de todas las actividades que contempló la aplicación de la estrategia educativa reportada. Los elementos que fueron evaluados puntualmente durante el proceso de análisis textual fueron los relacionados con la idea u objetivo central de la química verde, los supuestos sobre el tema y los propósitos que busca cumplir el texto divulgativo en el público lector. Mientras que, lo relativo a conceptos, inferencias, manejo de información, puntos de vista e implicaciones y consecuencias socioambientales del tema se valoraron de forma transversal. En la tabla 3, se muestran los puntajes promedio conseguidos en el desarrollo de los ocho elementos del pensamiento crítico con la rúbrica utilizada, resultados que son representados gráficamente en la figura 4.

Tabla 3

Promedios obtenidos al evaluar el desarrollo de elementos de pensamiento crítico $(n=11)$

\begin{tabular}{lll}
\hline $\begin{array}{l}\text { Elementos del pensamiento } \\
\text { crítico }\end{array}$ & $\begin{array}{l}\text { Puntaje promedio con la } \\
\text { rúbrica }\end{array}$ & $\begin{array}{l}\text { Desviación } \\
\text { estándar }\end{array}$ \\
\hline Idea central & 3.18 & \pm 0.6 \\
Supuestos & 2.27 & \pm 0.65 \\
Inferencias & 2.45 & \pm 0.52 \\
Conceptos & 2.64 & \pm 0.47 \\
Información & 2.82 & \pm 0.69 \\
Propósito & 2.91 & \pm 0.54 \\
Puntos de vista & 3.09 & \pm 0.74 \\
Implicaciones & 3.55 & \pm 0.52 \\
Puntuación total & 22.91 & \pm 1.4 \\
\hline
\end{tabular}

Como se puede observar en la gráfica de la figura 4, los alumnos exhibieron un desempeño regular o intermedio en el desarrollo de elementos de pensamiento crítico sobre la química verde. Los elementos donde se registró el aprovechamiento más bajo fueron supuestos, inferencias y conceptos donde se obtuvieron puntajes promedio de 2.27, 2.45 y 2.64 respectivamente. Mientras que, la puntuación promedio más alta (3.55), se obtuvo en el análisis de las implicaciones socioambientales del tema, es decir, en la revisión de su dimensión contextual. El bajo desempeño en lo relativo a supuestos e inferencias se debió a que estos elementos estaban relacionados con la elaboración de argumentos y cuestionamientos sobre el tema, un 
rubro donde los alumnos mostraron un desempeño moderado como se describe al informar lo conseguido sobre habilidades argumentativas.

\section{Figura 4}

Gráfica que muestra el nivel de desarrollo de los elementos del pensamiento crítico $(n=11)$

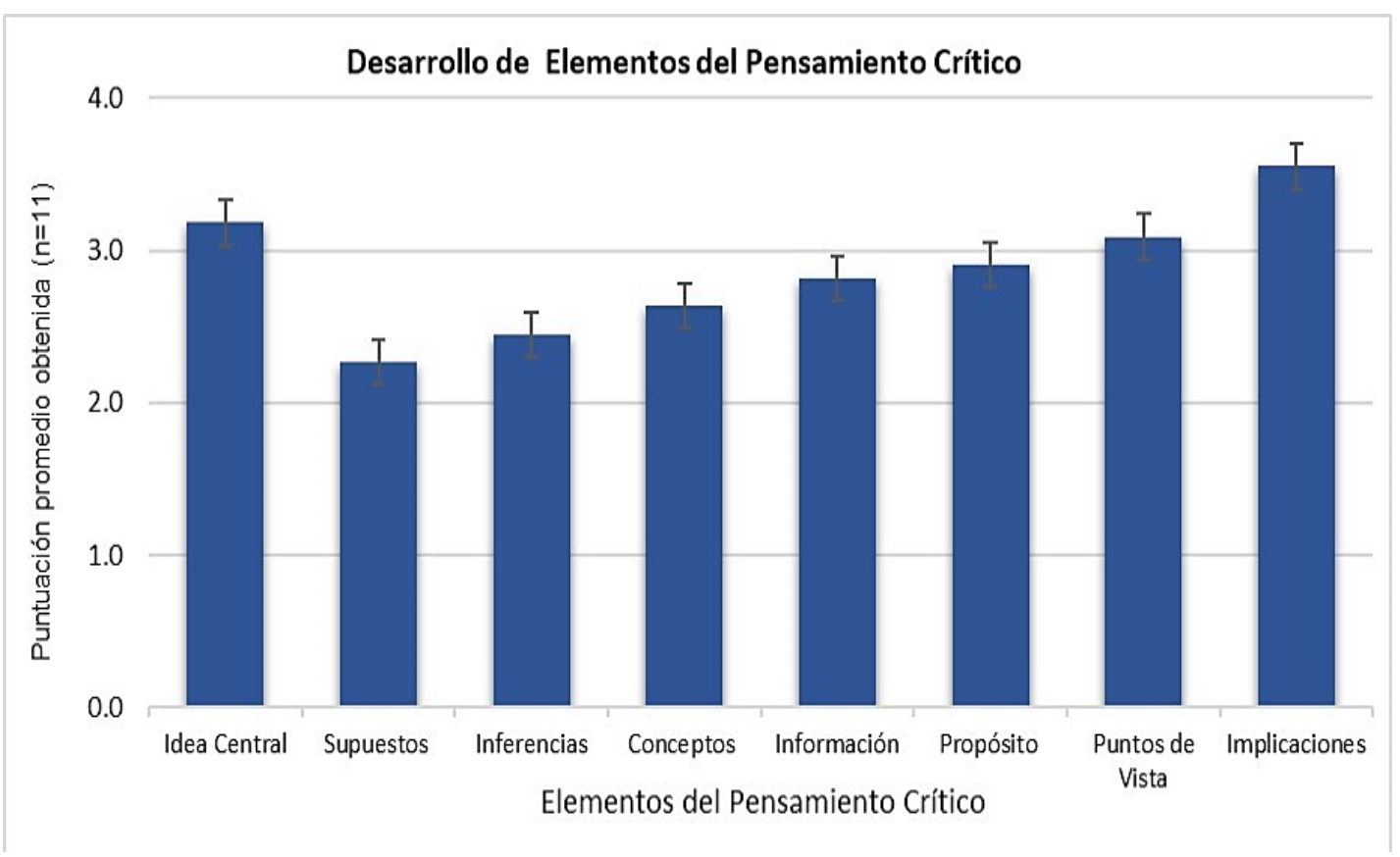

En lo referente a conceptos, se atestiguó que la realización de la actividad experimental contribuyó a un mayor dominio de los principios y nociones disciplinares asociadas con el estudio de la química verde. Gracias a la tabla de evaluación para interpretar el experimento (Vargas et al., 2016), los estudiantes identificaron que la reacción de descomposición del agua oxigenada utilizando como catalizador a la enzima catalasa presente en hortalizas ricas en almidón como la papa cumple un rango de 7 a 9 principios de la química verde. Los principios (P) cuyo cumplimiento reconocieron en esta reacción los 11 equipos de trabajo con la tabla de evaluación utilizada fueron P3, P4, P5, P6, P8, P9, y P12 y con variaciones y menos claridad P7 y P10 (anexo 1). Por su parte, todos los equipos de trabajo coincidieron que cuando se realiza esta misma reacción con un catalizador tradicional como el óxido de manganeso IV (MnO2), la reacción se torna altamente tóxica por la presencia del manganeso, provocando el incumplimiento de la mayoría de los principios de la química verde. A pesar de exhibir una adecuada comprensión de los conceptos implicados en el estudio de la química verde, se registró una puntuación promedio baja de este elemento. Esto se debió al poco uso de información disciplinar en la elaboración de argumentos.

El buen desempeño en el análisis de la parte contextual de tema se relaciona con el hecho de que los jóvenes pudieron reunir cifras y datos relevantes al exponer la importancia del reciclado del PET en México y vincular este proceso con los postulados de la química verde relacionados con la disminución de residuos y la maximización de materias primas (P1 y P11) en los productos de la tercera sesión metodológica. Asimismo, fueron capaces de construir argumentos y expresar opiniones validas sobre las contribuciones que este campo de conocimiento químico puede hacer al cuidado del medio ambiente. Al sumar el promedio del puntaje obtenido en el desarrollo de los ocho elementos del pensamiento crítico en los 11 equipos de trabajo, se obtuvo un valor de 22.91 de los 32 posibles en la rúbrica utilizada (anexo 1). Esta puntuación indica que, los alumnos lograron desarrollar el $71.5 \%$ de las habilidades estipuladas en este instrumento de evaluación.

\subsection{Habilidades argumentativas}

En la argumentación individual sobre el tema, se observó un desempeño similar al descrito con anterioridad. Los estudiantes exhibieron habilidades que fueron situadas en niveles intermedios al explicitar una posición sobre la relevancia disciplinar y educativa de la química verde en los escritos realizados de forma individual. En la figura 5, se muestran los puntajes obtenidos con la rúbrica utilizada para evaluar habilidades argumentativas. 
Figura 5

Desempeño individual observado sobre habilidades argumentativas en torno la química verde $(n=45)$

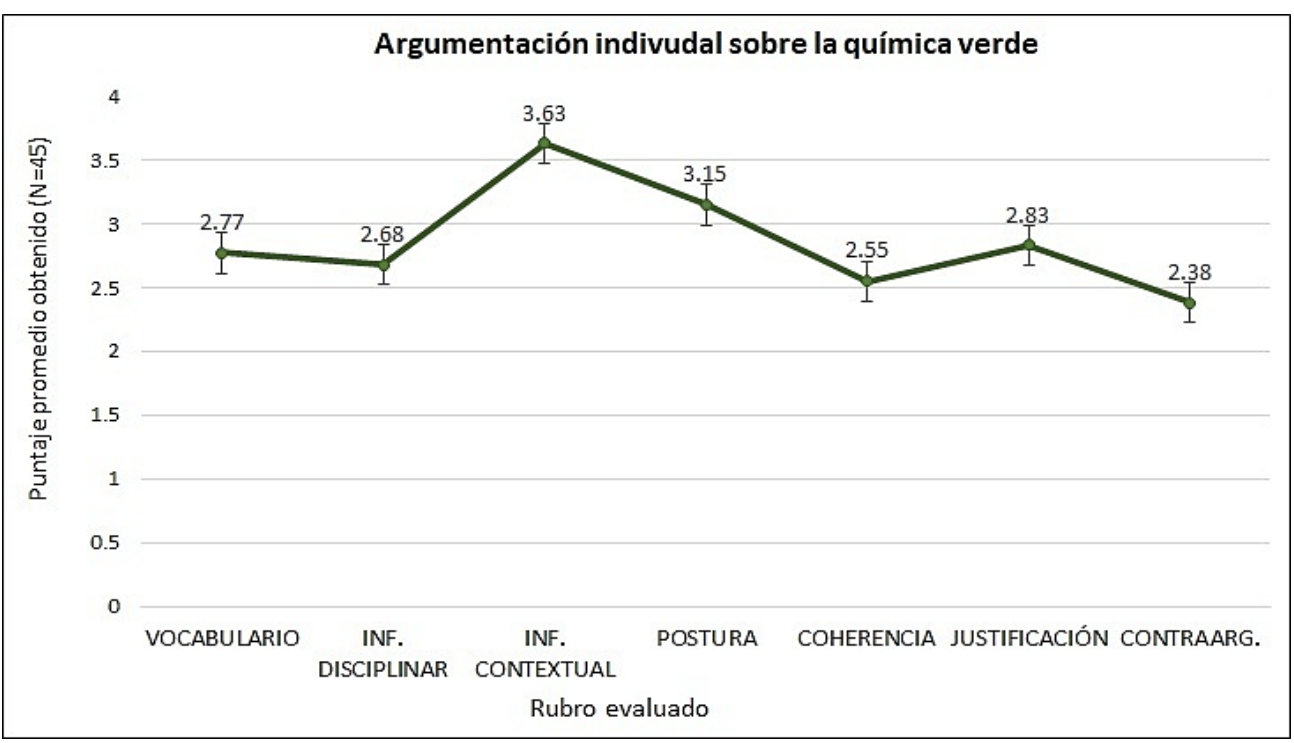

Como se puede observar en la gráfica de la figura 5, el rubro de menor desempeño fue el de contraargumentación donde se obtuvo un puntaje promedio de 2.38 y el de mayor aprovechamiento fue nuevamente el concerniente a información contextual del tema donde el puntaje registrado con la rúbrica correspondiente fue de 3.63. El bajo puntaje obtenido en lo relacionado con contraargumentación informó que a los alumnos se les dificultó establecer y discutir disensos o información controvertida sobre el tema. Otro aspecto muy notorio en la revisión de los escritos escolares fue el limitado nivel de coherencia en la redacción de argumentos en general, un problema que tiene su origen en el pobre hábito de escritura que poseen los alumnos de este nivel de estudios en el sistema educativo mexicano.

En general, en los escritos se pudo observar que los alumnos lograron recopilar información relevante sobre la temática en cuestión, cierto dominio sobre los contenidos disciplinares implicados, la identificación de diferentes puntos de vista, el establecimiento de acuerdos y, aunque con marcadas limitaciones, la reconsideración de algunas afirmaciones. Estos resultados mostraron indicios de la construcción de una interpretación reflexiva de la química verde en los estudiantes que participaron en este estudio. Al sumar el promedio alcanzado en los 7 apartados presentes en el instrumento de evaluación utilizado, se observó que los alumnos cubrieron poco más del $70 \%$ de las habilidades contempladas. Las coincidencias encontradas en la evaluación de las actividades cooperativas y en la argumentación individual sobre el tema, muestran consistencia en el desempeño reportado en general.

Finalmente, en lo concerniente al aprendizaje actitudinal, este fue registrado en una bitácora de seguimiento. En los cuatros sesiones de trabajo, se pudo observar apertura tanto al aprendizaje del tema como a las fuentes de consulta utilizadas, respeto, tolerancia, disposición al diálogo y responsabilidad al efectuar las actividades planteadas.

\section{Discusión y conclusiones}

Comunicar aspectos sobre la química verde en el bachillerato a través del análisis crítico de un texto divulgativo -La Química Verde de Ruíz-Loyola y Ruíz-Gutiérrez (2011)-, se develó como una ruta educativa benéfica y pertinente. Debido a que, la revisión de los contenidos de este material de lectura permitió referenciar en el salón de clases algunos procesos de síntesis que se caracterizan por ser más limpios y eficientes que los convencionales, así como algunas acciones metodológicas que se están consolidando en la investigación química con miras de hacer contribuciones al paradigma de desarrollo sostenible. La problematización de este texto mediante actividades basadas en la indagación hizo posible también que, los estudiantes corroborarán experimentalmente la importancia que posee el uso de catalizadores en la química y recopilarán información documental en torno a cursos de acción de relevancia industrial en donde la reutilización de materias primas adquiere relevancia, como es el caso del reciclado del polímero PET.

Es importante mencionar que tanto las actividades como el estudio de los contenidos antes mencionados, estuvieron enraizados en el reconocimiento del contexto de aplicación de los 12 principios 
que dan sustento a la química verde. Un hecho que favoreció la comprensión de la importancia disciplinar del tema, la reflexión sobre su viabilidad y el reconocimiento del importante papel que tiene la química en la resolución de problemas vinculados con el cuidado del planeta. Logros que coadyuvaron en la formación de una conciencia ambiental en los estudiantes que participaron en esta investigación. Incentivar la adquisición de una conciencia ambiental y dar cauce a contenidos que guardan relación con el desarrollo sostenible son objetivos que algunos autores señalan como prioritarios de la educación científica contemporánea (Mascarell y Vilches, 2016; Rodríguez, 2018).

Otro aspecto a resaltar de la propuesta metodológica presente en esta investigación es la buena aceptación que generó en los estudiantes el material de lectura seleccionado y las actividades implementadas en su decodificación. Se confirmó lo que señalan algunos autores respecto al uso de textos provenientes del campo de la comunicación pública de la ciencia en entornos escolares, esto es, que favorecen los procesos de enseñanza contextualizada de contenidos científicos con amplia relevancia social, incrementan el interés por la ciencia y permiten diversificar el acervo de recursos textuales que se pueden utilizar en la educación científica en niveles básicos e intermedios (Halkia y Mantzouridis, 2005; Cassany, 2010; McClune, 2017; Meinguer, 2019). Sin embargo, para incentivar la construcción de aprendizajes sólidos y reflexivos con este tipo de fuentes es necesario que las estrategias de lectura o análisis sean producto de un riguroso proceso de planeación didáctica y disciplinar por parte del profesorado (Oliveras et al., 2013).

En lo concerniente al desarrollo de elementos de pensamiento crítico sobre la química verde, se encontró que la articulación de aprendizajes conceptuales y contextuales en la implementación de la estrategia educativa, posibilitó que los estudiantes exhibieran su adquisición en un nivel intermedio. Otro elemento que contribuyó en la consecución de este resultado fue que la aplicación del trabajo metodológico se dio en un marco pedagógico donde se priorizó el trabajo colaborativo, el diálogo, la interacción, la argumentación y la participación escolar. Con respecto a los instrumentos de evaluación utilizados, estos resultaron consistentes con las actividades emprendidas por los estudiantes e hicieron posible una valoración cualitativa, progresiva y flexible de los alcances conseguidos en materia de pensamiento crítico, tal como se recomienda en la literatura especializada en el campo (Paul y Elder, 2007; Ossa-Cornejo et al., 2017). Se considera que la evaluación del aprendizaje actitudinal es un aspecto que debe ser mejorado e integrado con mayor formalidad en el esquema de evaluación propuesto en este trabajo. A pesar de lo anterior, fue posible observar apertura, compromiso, responsabilidad y un papel activo en los estudiantes al construir aprendizajes en el trabajo escolar.

Los resultados informados en esta investigación muestran que diseñar e implementar estrategias educativas que favorezcan el desarrollo del pensamiento crítico en la educación científica es una labor compleja de emprender, pues demanda una formación docente que va más allá del dominio teórico o disciplinar de un tema. Los autores de este estudio consideramos que tanto la metodología como los resultados comunicados son perfectibles y pueden fungir como una guía de consulta útil para los académicos interesados en promover el pensamiento crítico, la lectura y una enseñanza contextualizada de la química en particular y de la ciencia en general en el bachillerato.

\section{Referencias}

Alvarado, P. (2014). El desarrollo del pensamiento crítico: una necesidad en la formación de los estudiantes universitarios. DID $A C$ (nueva época), 64, 10-17.

Anastas, P. \& Warner, J. (1998). Green Chemistry: Theory and Practice. Oxford University Press.

Boisvert, J. (2004). La formación del pensamiento crítico: teoría y práctica. Fondo de Cultura Económica.

Cassany, D. (2010). Diez claves para enseñar a interpretar. Leer para aprender. Leer en la era digital. Ministerio de Educación. Recuperado https://sede.educacion.gob.es/publiventa/ImageServlet?img=13939.pdf\&D=OK

Code, L. (2011). Responsabilismo. En M. Valdés y M. Fernández, Normas, Virtudes y Valores Epistémicos (pp. 279-298). Instituto de Investigaciones Filosóficas-UNAM.

García-Díaz, E., Fernández-Arroyo, J., Rodríguez-Marín, y Puig, M. (2019). Más allá de la sostenibilidad: por una Educación Ambiental que incremente la resiliencia de la población ante el decrecimiento, Revista de Educación Ambiental y Sostenibilidad, 1(1), 1101-11015.

http://dx.doi.org/10.25267/Rev_educ_ambient_sostenibilidad.2019.v1.11.1101

Garritz, A. (2010). Indagación: las habilidades para desarrollarla y promover el aprendizaje. Educación química, 21(2), 106-110.

Gatica-Lara, F., y Uribarren-Berrueta, T. (2013). ¿Cómo elaborar una rúbrica? Investigación en educación médica, 2(5), 61-65. 
Gil, D. y Vilches, A. (2019). La comprensión e impulso de la Sostenibilidad: Un requisito para una acción educativa y ciudadana eficaz. Revista De Educación Ambiental Y Sostenibilidad, 1(2), 2101-1-2101-14. https://doi.org/10.25267/Rev_educ_ambient_sostenibilidad.2019.v1.i2.2101

Gordillo, M. (2005). Cultura científica y participación ciudadana: materiales para la educación CTS. Revista Iberoamericana de Ciencia, Tecnologia y Sociedad, 2(6), 123-135.

Halkia, Kr. \& Mantzouridis, D. (2005). Students' views and attitudes towards the communication code used in press articles about science. International Journal of Science Education, 27(12), 1395-1411. https://doi.org/10.1080/09500690500102912

Herrera, A. (2008). La situación de la enseñanza del pensamiento crítico. Pasado, presente y futuro de la enseñanza del pensamiento crítico en México, Ergo (nueva época), 2, 15-50.

Jarman, R. \& McClune, B. (2007). Developing Scientific Literacy: Using News Media In The Classroom. McGrawHill Education.

Jiménez-Aleixandre, M. \& Puig, B. (2012). Argumentation, evidence evaluation and critical thinking. In B.I. Fraser, K. Tobin \& C.J. McRobbie (Eds.), Second international handbook of science education (pp. 1001-1015). Springer, Dordrecht. http://dx.doi.org/10.1007/978-1-4020-9041-7_66

Kant, I. (2002). Crítica de la razón pura. Tecnos.

Marbá, A., Márquez, C. y Sanmartí, N. (2009). ¿Qué implica leer en clase de ciencias? Alambique, 59, 102111.

Mascarell, L. y Vilches, A. (2016). Química Verde y Sostenibilidad en la educación en ciencias en secundaria. Enseñanza de las ciencias: revista de investigación y experiencias didácticas [en linea], 34(2), 25-42. Recuperado de https://www.raco.cat/index.php/Ensenanza/article/view/309278

McClune, B. (2017). Committing curriculum time to science literacy: The benefits from science based media resources. The Journal of Emergent Science, 12, 25-40. Recuperado de https://n9.cl/x504o

McClune, B. \& Jarman, R. (2012). Encouraging and equipping students to engage critically with science in the news: what can we learn from the literature? Studies in Science Education, 48(1), 1-49. https://doi.org/10.1080/03057267.2012.655036

Meinguer, J. (2018). El valor del pensamiento crítico en la educación científica. Eutopía, 11(29), 5-11.

Meinguer, J. (2019). La comunicación de la nanotecnología a través del análisis crítico de textos informales. Mundo Nano. Revista Interdisciplinaria en Nanociencia y Nanotecnología, 12(22), 3-35. https://doi.org/10.22201/ceiich.24485691e.2019.22.61953

Meinguer, J. (2015). La virtud, un paradigma filosófico loable en la educación química. Educación quimica, 26(1), 43-49. https://doi.org/10.1016/S0187-893X(15)72097-5

Morales, M., Martínez, J., Reyes, L., Martín O., Arroyo, G., Obaya, A. y Miranda, R. (2011). ¿Qué tan verde es un experimento? Educación química, 22(3), 240-248.

Norris, S., Phillips, L. \& Korpan, C. (2003). University students' interpretation of media reports of science and its relationship to background knowledge, interest, and reading difficulty. Public Understanding of Science, 12(2), 123-145. https://doi.org/10.1177/09636625030122001

OECD iLibrary. (2007). Programme for International Student Assessment's, (PIS A) periodic testing program on student performance. Science Competencies for Tomorrow's World, vol. I: Analysis. Organisation for Economic Cooperation and Development. Recuperado de https://www.oecd.org/unitedstates/39722597.pdf

ONU (1987). Nuestro futuro comun. Informe Brundtland. Recuperado de https://undocs.org/es/A/42/427

ONU (2000). Declaración del milenio, quincuagésimo periodo de sesiones. Recuperado de https://www.un.org/spanish/milenio/ares552.pdf

ONU (2019). Informe Mundial sobre el Desarrollo Sostenible 2019: El futuro es abora-la ciencia al servicio del desarrollo sostenible —. Grupo independiente de científicos designados por el Secretario General. Naciones Unidas. Recuperado de https://n9.cl/74z0

Oliveras, B., Márquez, C. y Sanmartí, N. (2013). The Use of Newspaper Articles as a Tool to Develop Critical Thinking in Science Classes, International Journal of Science Education, 35(6), 885-905.

https://doi.org/10.1080/09500693.2011.586736

Ossa-Cornejo, C., Palma, M., Lagos N., Quintana, I. y Díaz C. (2017). Análisis de instrumentos de medición del pensamiento crítico. Ciencias psicológicas, 11(1), 19-28. https://doi.org/10.22235/cp.v11i2.1343

Paul, R. \& Elder, L. (2006). The Miniature Guide to Critical Thinking-Concepts \& Tools. Foundation for Critical Thinking. Recuperado de https://www.criticalthinking.org/files/Concepts_Tools.pdf

Paul, R. \& Elder, L. (2007). A guide for educators to critical thinking competency standards. Foundation for Critical Thinking. Recuperado de https://www.dphu.org/uploads/attachements/books/books_5519_0.pdf

Reyes-Sánchez, L. B. (2012). Aporte de la química verde a la construcción de una ciencia socialmente responsable. Educación química, 23(2), 222-229.

https://doi.org/10.1016/S0187-893X(17)30113-1 
Ribeiro, G. y Machado, A. (2013). Holistic metrics for assessment of the greenness of chemical reactions in the context of chemical education, Journal of Chemical Education, 90(4), 432-439. https://doi.org/10.1021/ed300232w

Rodríguez, B. (2018). Enseñanza de la química sostenible en las carreras de ingeniería. Revista de Química PUCP, 32(1), 2-17.

Ruíz-Loyola, B. y Ruíz-Gutiérrez, J. (2011). La química verde. ¿Cómo ves? UNAM, 150, 30-33.

Santisteban, A. (2013). La investigación sobre el desarrollo de la competencia social y ciudadana para una participación crítica. En N. De-Alba-Fernández, F.F. García-Pérez y A. Santisteban (Coords.), Educar para la participación ciudadana en la enseñanza de las ciencias sociales (pp. 277-286). Díada Editora. Recuperado de https://dialnet.unirioja.es/servlet/articulo?codigo $=3977777$

Sierra, A., Meléndez, L., Ramírez-Monroy, A. y Arroyo, M. (2014). La química verde y el desarrollo sustentable. RIDE Revista Iberoamericana para la Investigación y el Desarrollo Educativo, 5(9), 1-15.

UNAM-CCH. (2016). Programas de Estudio de Ciencias Experimentales: Química III-IV. México. Recuperado de http://www.cch.unam.mx/sites/default/files/programas2016/QUIMICA_III_IV.pdf

UNESCO (2017). Education for Sustainable Development Goals. Learning Objectives. UNESCO. Recuperado de https://unesdoc.unesco.org/ark:/48223/pf0000247444?utm_sq=gj34xbfn94

Vargas-Rodríguez, Y., Obaya, A., Vargas, S., Escamilla, A., Ruvalcaba, R. y Rodríguez, G. (2016). El diagrama de flujo como semáforo de seguridad ecológica de los experimentos de laboratorio. Educación quimica, 27(1), 30-36. http://dx.doi.org/10.1016/j.eq.2015.04.013

Vilches, A. \& Gil-Pérez, D. (2013). Creating a sustainable future: some philosophical and educational considerations for chemistry teaching. Science \& Education, 22(7), 1857-1872.

https://doi.org/10.1007/s11191-011-9404-x

Wright, I. (2002). Critical Thinking in the Schools: Why Doesn't Much Happen? Informal Logic, 22(2), 137154. 
Anexo I. Instrumentos de evaluación

a) Rúbrica para evaluar el desarrollo de elementos de pensamiento crítico. ${ }^{1}$

\begin{tabular}{|c|c|c|c|c|}
\hline Aspectos & 1. Deficiente & $\begin{array}{l}\text { 2. Bajo } \\
\text { desempeño }\end{array}$ & $\begin{array}{l}\text { 3. Desempeño } \\
\text { regular }\end{array}$ & $\begin{array}{c}\text { 4. Desempeño } \\
\text { optimo o } \\
\text { excelente }\end{array}$ \\
\hline $\begin{array}{l}\text { Pregunta o idea } \\
\text { central }\end{array}$ & $\begin{array}{l}\text { Se cita información } \\
\text { irrelevante en torno } \\
\text { al tema central del } \\
\text { texto divulgativo. }\end{array}$ & $\begin{array}{l}\text { Identifican } \\
\text { parcialmente el tema } \\
\text { o idea central del } \\
\text { texto divulgativo. }\end{array}$ & $\begin{array}{l}\text { Identifican } \\
\text { correctamente el } \\
\text { tema o idea central } \\
\text { del texto divulgativo }\end{array}$ & $\begin{array}{l}\text { Identifican de forma } \\
\text { clara, precisa y } \\
\text { correcta el tema o idea } \\
\text { central del texto } \\
\text { divulgativo. }\end{array}$ \\
\hline Propósito & $\begin{array}{l}\text { No identifican el } \\
\text { propósito que } \\
\text { pretende cumplir el } \\
\text { texto en el público } \\
\text { lector. }\end{array}$ & $\begin{array}{l}\text { Identifican de forma } \\
\text { ambigua el } \\
\text { propósito que } \\
\text { pretende cumplir el } \\
\text { texto en el público } \\
\text { lector. }\end{array}$ & $\begin{array}{l}\text { Identifican con } \\
\text { claridad el propósito } \\
\text { que pretende } \\
\text { cumplir el texto en } \\
\text { el publico lector y } \\
\text { explicitan virtudes y } \\
\text { limitaciones de la } \\
\text { publicación. }\end{array}$ & $\begin{array}{l}\text { Identifican } \\
\text { claridad el propósito } \\
\text { que pretende cumplir } \\
\text { el texto en el público } \\
\text { lector, así como la } \\
\text { importancia de las } \\
\text { ideas y valores } \\
\text { asociados con la } \\
\text { publicación. }\end{array}$ \\
\hline Supuestos & $\begin{array}{l}\text { Formulan } \\
\text { conjeturas } \\
\text { suposiciones } \\
\text { erróneas sobre la } \\
\text { temática } \\
\text { cuestión, en } \\
\text { resultan } \\
\text { inconsistentes con la } \\
\text { información y el } \\
\text { contexto revisado } \\
\text { en su análisis. }\end{array}$ & $\begin{array}{l}\text { Formulan } \\
\text { conjeturas } \\
\text { suposiciones } \\
\text { ambiguas sobre la } \\
\text { temática } \\
\text { cuestión, ya que } \\
\text { muestran en } \\
\text { validez con la } \\
\text { información y el } \\
\text { contexto revisado } \\
\text { en su análisis. }\end{array}$ & $\begin{array}{l}\text { Formulan } \\
\text { conjeturas o } \\
\text { suposiciones validas } \\
\text { sobre la temática en } \\
\text { cuestión, las cuales } \\
\text { guardan relación } \\
\text { con la información y } \\
\text { el contexto revisado } \\
\text { en su análisis. }\end{array}$ & $\begin{array}{l}\text { Formulan conjeturas } \\
\text { o suposiciones } \\
\text { correctas y validas } \\
\text { sobre la temática en } \\
\text { cuestión, las cuales } \\
\text { resultan pertinentes } \\
\text { con la información yel } \\
\text { contexto revisado en } \\
\text { su análisis. }\end{array}$ \\
\hline Inferencias & $\begin{array}{l}\text { Citan frases literales } \\
\text { del texto divulgativo } \\
\text { sin inferir la } \\
\text { posición del autor. } \\
\text { Sus argumentos o } \\
\text { cuestionamientos } \\
\text { sobre la temática } \\
\text { estudiada resultan } \\
\text { erróneos y/o } \\
\text { irrelevantes. }\end{array}$ & $\begin{array}{l}\text { Muestran } \\
\text { limitaciones para } \\
\text { inferir la posición } \\
\text { del autor del texto } \\
\text { divulgativo, así } \\
\text { como para construir } \\
\text { cuestionamientos o } \\
\text { argumentos válidos } \\
\text { sobre la temática } \\
\text { estudiada. }\end{array}$ & $\begin{array}{l}\text { Infieren la posición } \\
\text { del autor del texto } \\
\text { divulgativo, pero } \\
\text { manifiestan } \\
\text { deficiencias para } \\
\text { construir } \\
\text { cuestionamientos o } \\
\text { argumentos válidos } \\
\text { sobre la temática } \\
\text { estudiada. }\end{array}$ & $\begin{array}{l}\text { Infieren con claridad } \\
\text { la posición del autor } \\
\text { del texto divulgativo y } \\
\text { muestran dominio } \\
\text { para construir } \\
\text { cuestionamientos o } \\
\text { argumentos válidos } \\
\text { sobre la temática } \\
\text { estudiada. }\end{array}$ \\
\hline Conceptos & 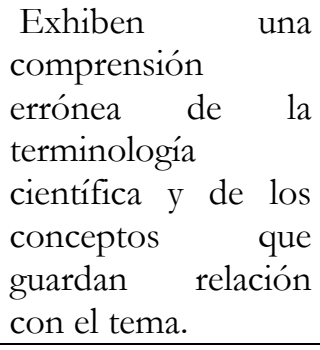 & 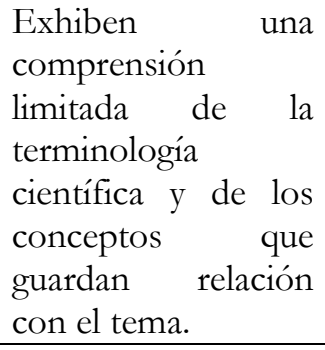 & 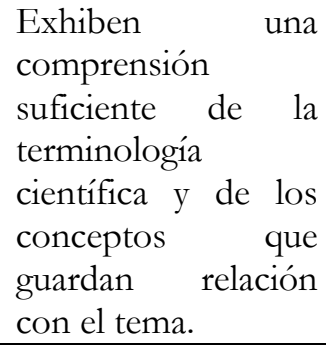 & $\begin{array}{l}\text { Exhiben un dominio } \\
\text { amplio de la } \\
\text { terminología científica } \\
\text { y los conceptos que } \\
\text { guardan relación con } \\
\text { el tema. }\end{array}$ \\
\hline Información & $\begin{array}{l}\text { Muestran } \\
\text { dificultades para } \\
\text { identificar datos, } \\
\text { hechos y evidencias } \\
\text { en el análisis de la }\end{array}$ & $\begin{array}{l}\text { Muestran } \\
\text { habilidades } \\
\text { limitadas para } \\
\text { identificar datos, } \\
\text { hechos y evidencias, }\end{array}$ & $\begin{array}{l}\text { Muestran } \\
\text { habilidades } \\
\text { suficientes para } \\
\text { identificar los datos, } \\
\text { hechos y evidencias, }\end{array}$ & $\begin{array}{lr}\text { Muestran } & \text { amplio } \\
\text { dominio } & \text { para } \\
\text { identificar datos, } \\
\text { hechos y evidencias, } \\
\text { así como para evaluar }\end{array}$ \\
\hline
\end{tabular}

${ }^{1}$ Rúbrica basada en los indicadores de Paul y Elder (2007). 


\begin{tabular}{|c|c|c|c|c|}
\hline & $\begin{array}{l}\text { temática presentada } \\
\text { en el texto } \\
\text { divulgativo. }\end{array}$ & $\begin{array}{l}\text { así como para } \\
\text { evaluar afirmaciones } \\
\text { en el análisis de la } \\
\text { temática presentada } \\
\text { en el texto } \\
\text { divulgativo. }\end{array}$ & $\begin{array}{l}\text { así como para } \\
\text { evaluar afirmaciones } \\
\text { en el análisis de la } \\
\text { temática presentada } \\
\text { en el texto } \\
\text { divulgativo. }\end{array}$ & $\begin{array}{l}\text { afirmaciones en el } \\
\text { análisis de la temática } \\
\text { presentada en el texto } \\
\text { divulgativo. }\end{array}$ \\
\hline Puntos de Vista & $\begin{array}{l}\text { Reconocen un solo } \\
\text { punto de vista (el del } \\
\text { autor) respecto al } \\
\text { tema expuesto en el } \\
\text { texto y lo toman } \\
\text { como cierto e } \\
\text { incuestionable. }\end{array}$ & $\begin{array}{l}\text { Reconocen con } \\
\text { cierta ambigüedad la } \\
\text { existencia de varios } \\
\text { puntos de vista } \\
\text { respecto al tema } \\
\text { expuesto en el texto. } \\
\text { No establecen con } \\
\text { claridad acuerdos y } \\
\text { desacuerdos en su } \\
\text { contrastación. }\end{array}$ & $\begin{array}{l}\text { Reconocen } \\
\text { diferentes puntos de } \\
\text { vista respecto al } \\
\text { tema expuesto en el } \\
\text { texto. Muestran } \\
\text { limitaciones para } \\
\text { establecer acuerdos } \\
\text { y desacuerdos en su } \\
\text { contrastación. }\end{array}$ & 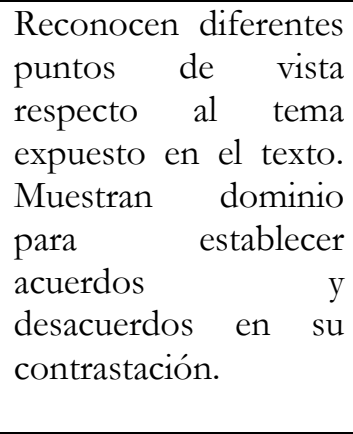 \\
\hline Implicaciones & $\begin{array}{lr}\text { Manifiestan } & \\
\text { dificultades } & \text { para } \\
\text { identificar } & \text { las } \\
\text { implicaciones } & \\
\text { tecnológicas, } & \\
\text { sociales } & \text { y } \\
\text { ambientales } & \text { que } \\
\text { guardan relación } \\
\text { con el tema. }\end{array}$ & $\begin{array}{lr}\text { Manifiestan } & \text { una } \\
\text { comprensión } & \\
\text { limitada de las } \\
\text { implicaciones } \\
\text { tecnológicas, } \\
\text { sociales } \\
\text { ambientales } \\
\text { guardan que } \\
\text { con el tema. } \\
\end{array}$ & $\begin{array}{lr}\text { Manifiestan una } \\
\text { comprensión } \\
\text { suficiente de las } \\
\text { implicaciones } \\
\text { tecnológicas, } \\
\text { sociales } \\
\text { ambientales que } \\
\text { guardan relación } \\
\text { con el tema. } \\
\end{array}$ & $\begin{array}{l}\text { Manifiestan un amplio } \\
\text { dominio en la } \\
\text { comprensión de las } \\
\text { implicaciones } \\
\text { tecnológicas, sociales } \\
\text { y ambientales que } \\
\text { guardan relación con } \\
\text { el tema. }\end{array}$ \\
\hline
\end{tabular}

b) Rúbrica para evaluar habilidades de argumentación. ${ }^{2}$

\begin{tabular}{|c|c|c|c|c|c|}
\hline \multirow{2}{*}{\multicolumn{2}{|c|}{ Aspectos a evaluar }} & \multicolumn{4}{|c|}{ Niveles de desempeño } \\
\hline & & $\begin{array}{c}1 \\
\text { (Deficiente) }\end{array}$ & $\begin{array}{c}2 \\
\text { (Suficiente) }\end{array}$ & $\begin{array}{c}3 \\
\text { (Regular) }\end{array}$ & $\begin{array}{c}4 \\
\text { (Óptimo) }\end{array}$ \\
\hline 1. & Vocabulario & $\begin{array}{c}\text { El uso que hace de } \\
\text { las palabras es } \\
\text { inapropiado y } \\
\text { confuso. }\end{array}$ & $\begin{array}{l}\text { El uso que hace de } \\
\text { las palabras es } \\
\text { reiterativo. }\end{array}$ & $\begin{array}{c}\text { El uso que hace de } \\
\text { las palabras es } \\
\text { preciso. }\end{array}$ & $\begin{array}{l}\text { El uso que hace } \\
\text { del lenguaje es } \\
\text { amplio y } \\
\text { apropiado. } \\
\end{array}$ \\
\hline & $\begin{array}{l}\text { Información } \\
\text { disciplinar }\end{array}$ & $\begin{array}{l}\text { Hay ausencia de } \\
\text { conceptos } \\
\text { disciplinares clave } \\
\text { sobre el tema. }\end{array}$ & $\begin{array}{c}\text { Utiliza de manera } \\
\text { limitada la } \\
\text { información } \\
\text { disciplinar en } \\
\text { torno al tema. }\end{array}$ & $\begin{array}{c}\text { Reconoce de } \\
\text { manera correcta } \\
\text { conceptos } \\
\text { científicos clave, } \\
\text { pero se hace poco } \\
\text { uso de ellos. }\end{array}$ & $\begin{array}{c}\text { Utiliza la } \\
\text { información } \\
\text { disciplinar de } \\
\text { manera } \\
\text { apropiada y } \\
\text { suficiente en la } \\
\text { construcción de } \\
\text { argumentos. }\end{array}$ \\
\hline & $\begin{array}{l}\text { Información } \\
\text { contextual }\end{array}$ & $\begin{array}{l}\text { No reconoce la } \\
\text { presencia de } \\
\text { aspectos } \\
\text { contextuales sobre } \\
\text { el tema. }\end{array}$ & $\begin{array}{l}\text { Su dominio } \\
\text { contextual del } \\
\text { tema es pobre y } \\
\text { desarticulado. }\end{array}$ & $\begin{array}{c}\text { Reconoce } \\
\text { información } \\
\text { contextual } \\
\text { relevante, pero su } \\
\text { utilización es } \\
\text { limitada. }\end{array}$ & $\begin{array}{l}\text { Hace uso de la } \\
\text { información } \\
\text { contextual de } \\
\text { manera correcta } \\
\text { y apropiada en la } \\
\text { construcción de } \\
\text { argumentos. }\end{array}$ \\
\hline & Postura & $\begin{array}{c}\text { Ofrece } \\
\text { comentarios } \\
\text { generales. }\end{array}$ & $\begin{array}{l}\text { Comenta las } \\
\text { posturas y no } \\
\text { asume ninguna. }\end{array}$ & $\begin{array}{c}\text { Enuncia una } \\
\text { postura de manera } \\
\text { superficial (a favor } \\
\text { o en contra). }\end{array}$ & $\begin{array}{c}\text { Define } \\
\text { claramente una } \\
\text { postura y ofrece }\end{array}$ \\
\hline
\end{tabular}

2 Instrumento de evaluación reportado y empleado en Meinguer (2019b) 
una justificación

al defenderla.

5. Coherencia

Menciona ideas desconectadas $\mathrm{y} / \mathrm{o}$

contradictorias.

\section{Justificación}

Su afirmación o
rechazo se
sustenta en lo que
cree que es
verdadero.

\section{Hay una conexión \\ débil o ambigua en \\ los argumentos.}
Su afirmación o rechazo se

fundamenta en opiniones externas de orden común (creencias socioculturales).

\section{Sus argumentos \\ son consistentes, pero no congruentes.}

Su afirmación o rechazo se sustenta en experiencia o juicios personales que generaliza.

\section{Presenta}

consistencia y

congruencia en

su redacción.

Su afirmación o

rechazo se

sustenta en

evidencia

empírica y/o en

fuentes

documentales

acreditadas.

\begin{tabular}{|c|c|c|c|c|}
\hline 7. Contraargumentación & $\begin{array}{c}\text { Ausencia de } \\
\text { contraargumentaci } \\
\text { ón o refutaciones. }\end{array}$ & $\begin{array}{c}\text { Referencia de } \\
\text { manera trivial } \\
\text { aspectos } \\
\text { controvertidos a la } \\
\text { idea o posición } \\
\text { que defiende. }\end{array}$ & $\begin{array}{c}\text { Comenta algunos } \\
\text { aspectos } \\
\text { controvertidos y/o } \\
\text { contrarios a su } \\
\text { posición. }\end{array}$ & $\begin{array}{c}\text { Replantea } \\
\text { argumentos } \\
\text { basándose en los } \\
\text { puntos } \\
\text { controvertidos } \\
\text { y/o contrarios a } \\
\text { su posición. }\end{array}$ \\
\hline
\end{tabular}

c) Tabla de evaluación para identificar los principios de la Química Verde en experimentos escolares. ${ }^{3}$

\begin{tabular}{|c|c|c|c|c|}
\hline $\mathbf{N}^{\mathbf{o}}$ & $\begin{array}{c}\text { Principios de la Química } \\
\text { Verde }\end{array}$ & Principios para evaluar cada principio & SI & NO \\
\hline P1 & Prevención de residuos & $\begin{array}{l}\text { La eficiencia en masa o eficiencia en volumen } \\
\text { debe ser mínima (microescala). }\end{array}$ & & \\
\hline P2 & Economía atómica & $\begin{array}{l}\text { La mayor parte de las entidades atómicas en la } \\
\text { reacción deben formar parte del producto } \\
\text { principal. }\end{array}$ & & \\
\hline P3 & $\begin{array}{l}\text { Usar metodologías que generen } \\
\text { productos con toxicidad reducida }\end{array}$ & $\begin{array}{l}\text { La metodología experimental debe utilizar y } \\
\text { generar sustancias sin toxicidad (evaluar riesgos a } \\
\text { la salud y el ambiente). }\end{array}$ & & \\
\hline P4 & $\begin{array}{l}\text { Generar productos eficaces, pero } \\
\text { no tóxicos }\end{array}$ & $\begin{array}{l}\text { Los productos y/o residuos no deben ser tóxicos } \\
\text { (evaluar riesgos a la salud y el ambiente). }\end{array}$ & & \\
\hline P5 & $\begin{array}{l}\text { Reducir el uso de sustancias } \\
\text { auxiliares }\end{array}$ & $\begin{array}{l}\text { No utilizar sustancias auxiliares; si se utilizan, no } \\
\text { deben presentar riesgos a la salud y el medio } \\
\text { ambiente. }\end{array}$ & & \\
\hline P6 & Disminuir el consumo energético & $\begin{array}{l}\text { Los experimentos deben preferentemente } \\
\text { llevarse a cabo a temperatura y presión ambiente. }\end{array}$ & & \\
\hline P7 & Utilizar materias renovables & $\begin{array}{l}\text { Las materias primas deben ser preferiblemente } \\
\text { renovables. }\end{array}$ & & \\
\hline P8 & Evitar derivados innecesarios & $\begin{array}{l}\text { No utilizar derivados (evaluar riesgos a la salud y } \\
\text { el ambiente). }\end{array}$ & & \\
\hline P9 & Potenciar la catálisis & $\begin{array}{l}\text { Hacer uso de catalizadores para aumentar la } \\
\text { eficiencia de la reacción (evaluar la toxicidad del } \\
\text { catalizador o sistema catalítico). }\end{array}$ & & \\
\hline P10 & $\begin{array}{l}\text { Generar } \\
\text { biodegradables }\end{array}$ & $\begin{array}{l}\text { Los productos químicos y/o residuos deben ser } \\
\text { biodegradables (si no es biodegradable evaluar su } \\
\text { reutilización y toxicidad al ambiente). }\end{array}$ & & \\
\hline
\end{tabular}

3 Adaptación de la métrica reportada por Vargas y Obaya (2016). 


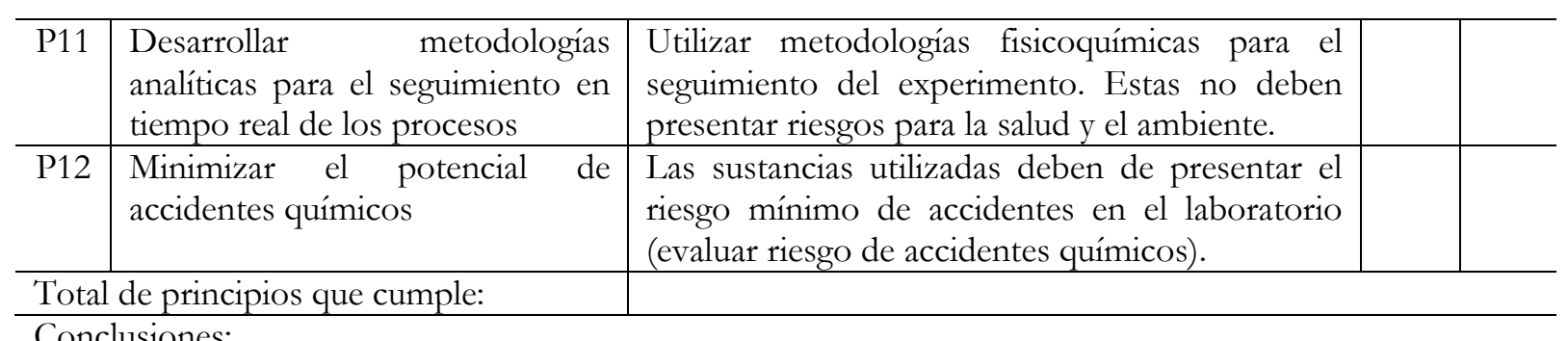

Conclusiones: 